\title{
SEQUÊNCIAS TECTONO-SEDIMENTARES MESOPALEOZÓICAS DA BACIA DO PARANÁ, SUL DO BRASIL
}

\author{
MARIO L. ASSINE*,PAULO C. SOARES* e ÉDISON J. MILANI**
}

\begin{abstract}
MIDDLE PALEOZOIC TECTO-SEDIMENTARY SEQUENCES OF THE PARANÁ BASIN, SOUTHERN BRASIL. This work presents a basinwide analysis on the Precarboniferous sequences of the Paraná basin. Sufarce and well data have been used to update geological interpretation and to suggest a new stratigraphic proposal for the Ordovician-Silurian of the Paraná basin. The diamictites, present in the Iapó, Vila Maria, and Rio Ivaí Formations, play important role in the new proposal, for they are interpreted as time correlate horizons related to Neo-Ordovician Gondwanan glaciations. It is herein proposed a gradational contact between the Furnas and Ponta Grossa Formations, as well as, the existence of a conspicuous unconformity in the Upper Silurian. The Precarboniferous of the Paraná basin is divided into two tectosedimentary sequences: 1 . an Ordovician-Silurian sequence (Rio Ivaí Group) composed of basal conglomerates and fluvial sandstones, overlain by coastal and marine sandstones (Alto Garças Formation). This sandy unit is covered by diamictites (Iapó Formation), and transgressive marine shales/coastal sandstones (Vila Maria Formation). The Rio Ivaí Group correlates with the Caacupé and Itacurubi Groups in Paraguay; 2. a Devonian sequence (Paraná Group) composed of a sandy unit (Furnas Formation) deposited by braid deltas, ending in a marine shaly unit (Ponta Grossa Formation). The Ponta Grossa Formation hás two maximum flooding surfaces bounded by prograding deltaic sandstones originating in East and Northeast sources.
\end{abstract}

Keywords: Paraná Basin, tecto-sedimentary sequences, Ordovician-Silurian, Devonian, Neo-Ordovician glaciation.

RESUMO Os sedimentos pré-carboníferos da Bacia do Paraná são analisados regionalmente, integrandose dados de superfície e subsuperfície. Novas correlações são aventadas e ressaltada a importância das ocorrências de diamictitos, incluídas anteriormente nas Formaçôes Iapó, Vila Maria e Rio Ivaí, como horizontes cronocorrelatos associados à glaciação gondwânica neo-ordoviciana. A natureza concordante do contato entre as Formações Furnas e Ponta Grossa é demonstrada, assim como a existência de uma expressiva discordância no Siluriano Superior, separando a Formação Furnas dos sedimentos ordovício-silurianos. São caracterizadas duas sequências tectono-sedimentares pré-carboníferas, separaradas por discordâncias regionais, constituindo dois grandes ciclos transgressivo-regressivos, incompletos no topo por erosão. A sequência ordovício-siluriana (Grupo Rio Ivaí) compreende conglomerados basais e arenitos fluviais sucedidos por arenitos litorâneos e marinhos rasos (Formação Alto Garças), sobrepostos por diamictitos (Formação Iapó), folhelhos marinhos transgressivos e arenitos litorâneos (Formacão Vila Maria), correlatos aos grupos Caacupé e Itacurubi, descritos na porção paraguaia da bacia. A sequência devoniana (Grupo Paraná) inicia-se com uma seção psamíticopsefítica (Formação Furnas), predominantemente continental, na base, e com crescente influência marinha em direção ao topo, depositada em deltas contruídos por rios entrelaçados. O empilhamento é retrogradacional culminando com o recobrimento por uma seção predominantemente pelítica marinha (Formação Ponta Grossa), onde distinguem-se duas superfícies de máxima inundação, separadas por arenitos deltaicos progradacionais provindos de leste e nordeste.

Palavras-chave: Bacia do Paraná, sequências tectono-sedimentares, Ordoviciano-Siluriano, Devoniano, glaciação neo-ordoviciana.

INTRODUÇÃO A implantação e o desenvolvimento inicial da Bacia do Paraná (Fig. 1) constituem aspectos dos menos conhecidos de sua geologia. No tocante à estratigrafia, há várias décadas foram identificados sedimentos ordovício-silurianos na porção sudoeste da bacia, em solo paraguaio, classificados dentro dos Grupos Caacupé e Itacurubi (Harrington 1972). No Brasil, abaixo dos folhelhos devonianos marinhos da Formação Ponta Grossa, ocorre a espessa seção arenosa da Formação Furnas. Por ser praticamente afossilífera, à exceção de icnofósseis de restrito valor cronoestratigráfico e palinomorfos constatados próximos ao seu topo, muitas têm sido as divergências quanto à sua idade (se devoniana ou siluriana) e relações estratigráficas (se concordante ou discordante com as formações Vila Maria e Ponta Grossa). Bigarella (1973), por exemplo, correlacionou-a com o Grupo Caacupé do Paraguai, atribuindo-lhe idade siluriana e posição estratigráfica discordante sob a Formação Ponta Grossa. Já, Soares et al. (1978) consideraram o Grupo Caacupé como a sequência cratônica basal da bacia, superposto em discordância pela Formação Furnas.
A Formação Furnas foi durante muitos anos considerada a unidade litoestratigráfica basal da bacia em sua porção brasileira, embora sedimentos subjacentes já tivessem sido constatados por Maack (1947), que descobriu diamictitos sob os arenitos conglomeráticos daquela unidade em afloramentos no Estado do Paraná. Para tais sedimentos, propôs a denominação Formação Iapó, sugerindo idade siluriana por correlação com unidades presentes no Grupo Table Mountain da África do Sul. Em subsuperfície, sedimentos sotopostos à Formação Furnas foram relatados por Maino (1965), a partir da constatação de arenitos avermelhados no intervalo 1702 a $1944 \mathrm{~m}$ do poço 2-AG-1-MT (Alto Garças).

Estes fatos, porém, não tiveram muita repercussão na comunidade geológica brasileira até que fosse comunicada, na segunda metade da década de 70 , a descoberta de sedimentos da Formação Vila Maria na borda norte da bacia (Faria \& Reis Neto 1978), considerada siluriana por Burjack e Popp (1981), em virtude da presença do icnofóssil Arthrophycus alleghaniensis.

\footnotetext{
* Departamento de Geologia, Universidade Federal do Paraná, Caixa Postal 19011, CEP 81531-990, Curitiba, PR, Brasil

** Nexpar/Petrobrás, Rua Padre Camargo, 285, CEP 80060-240, Curitiba, PR, Brasil
} 


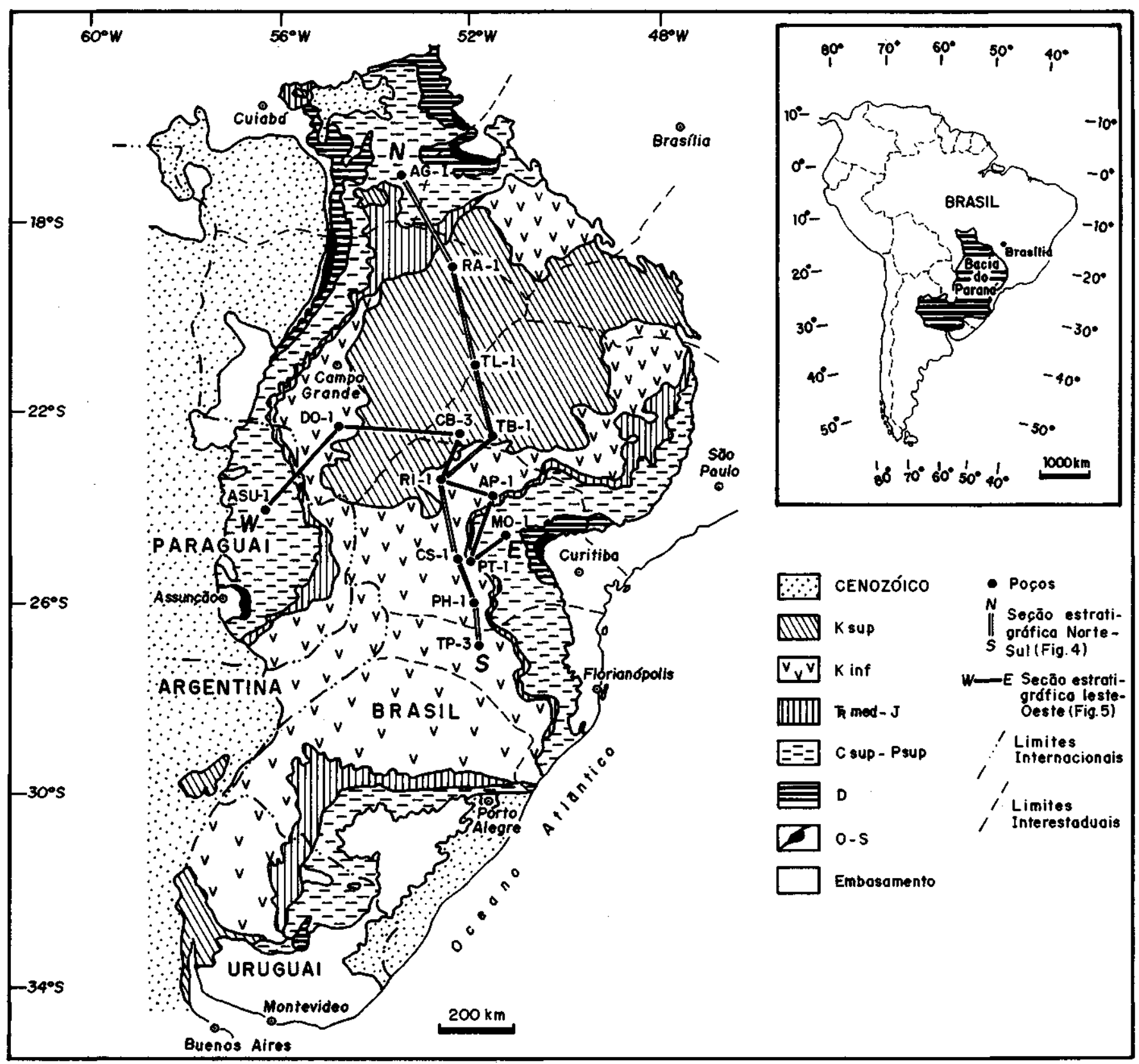

Figura 1 - Mapa geológico da Bacia do Paraná Figure 1 - Geological map of the Paraná basin

Tal descoberta deu início a uma série de trabalhos que permitiram significativo avanço no conhecimento das unidades mesopaleozóicas da bacia. Andrade \& Camarço (1980) correlacionaram os sedimentos da Formação Vila Maria com a seção psamítica situada abaixo da Formação Furnas no poço 2-AG-1-MT, em contato por eles admitido como concordante. Posteriormente, os mesmos autores (1982) atribuíram idade siluriana para toda a Formação Furnas. Faria (1982) apresentou a seção-tipo da Formação Vila Maria em superfície, estendendo também a denominação para os $242 \mathrm{~m}$ de sedimentos encontrados abaixo da Formação Furnas no poço 2-AG-1-MT. Considerou concordante o contato com a Formação Furnas, deixando subentender assim idade siluriana para esta última, pelo menos em sua porção basal.

Zalán et al. (1987), correlacionando perfis litológicos e petrofísicos, rastrearam a Formação Vila Maria em subsuperfície e dela subtraíram a seção arenosa basal, formalizada como Formação Rio Ivaí. Admitindo um contato discordante entre as Formações Furnas e Ponta Grossa, e concordante entre as Formações Furnas e Vila Maria, conceberam uma divisão tripartite do Siluriano da Bacia do Paraná, incluindo as Formações Rio Ivaí, Vila Maria e Furnas (Fig. 2).

Assine \& Soares (1989), a partir da análise de sequências de formatos de perfis de raios-gama e potencial espontâneo dos poços perfurados na bacia, questionaram a divisão tripartite do siluriano da Bacia do Paraná nos moldes em que foi estabelecida. Argumentando, ao contrário, a favor de contatos concordante entre as Formações Furnas e Ponta Grossa e discordante entre as Formações Vila Maria e Furnas, e rastreando os registros da glaciação neo-ordoviciana/eosiluriana (diamictitos das Formações Iapó e Vila Maria), apresentaram uma nova correlação estratigráfica (Fig. 3), da qual derivaram diversas novas concepções.

Este trabalho representa o desenvolvimento e consolidação das idéias trazidas à comunidade por Assine \& Soares 




Figura 2 - Correlação estratigráfica das unidades mesopaleozóicas segundo Zalán et al. (1987)

Figure 2 - Stratigraphic correlation of mesopaleozoic units. According to Zalán et al. (1987)

(1989). Nele são detalhados os critérios de correlação estratigráfica utilizados, destacando-se a importância dos registros glaciais como marcos estratigráficos e o reconhecimento das principais discordâncias. Âs sequências tectonosedimentares são analisadas estratigraficamente com a caracterização das unidades em superficie e subsuperficie. Ao mesmo tempo, são propostas alterações na nomenclatura litoestratigráfica formal dos sedimentos ordovíciosilurianos da porção brasileira da bacia.

MÉTODOS Muitas das controvérsias a respeito dos sedimentos pré-carboníferos da Bacia do Paraná advém do fato de que grande parte dos trabalhos realizados basearamse quase que exclusivamente em informações de superficie. $\mathrm{E}$ importante ressaltar que os empilhamentos observados no centro das bacias podem ser bastante diferentes, em termos de espessura e natureza das fácies sedimentares, daqueles existentes nas bordas. Nestas, movimentações tectônicas e variações do nível do mar alteram frequentemente o nível de base da erosão, dando origem a variações faciológicas derivadas de flutuação no aporte sedimentar e a descontinuidades não observadas no centro. Além disso, no caso específico da Bacia do Paraná, a área de ocorrência dos sedimentos pré-carboníferos é descontínua, limitando-se a afloramentos na área do Arco de Ponta Grossa em sua borda leste, os mais estudados, e a uma faixa em sua borda norte-noroeste.

Tendo em vista estas observações, os trabalhos realizados basearam-se na definição e correlação de padrões verticais de variação textural, pelo formato de perfis petrofísicos e litológicos de poços profundos. Os padrões observados fo- ram rastreados através da bacia e amarrados a seções de referência levantadas em superfície. Em virtude da escassez de dados paleontológicos nos intervalos basais, especialmente de subsuperficie, buscou-se estabelecer horizontes cronocorrelatos a partir da identificação de eventos marcantes preservados no registro sedimentar, tais como superficies de máxima inundação, descontinuidades e episódios glaciais, conforme apresentado preliminarmente por Soares (1991). Dados bioestratigráficos foram obtidos em intervalos-chave para correlação, sendo relatados por Milani et al. (trabalhos aceito).

Para melhor caracterizar as sequências tectono-sedimentares, a análise estratigráfica realizada envolveu toda a seção pré-carbonífera da bacia, com ênfase na sequência ordovício-siluriana.

GLACIAÇÃO NEO-ORDOVICIANA Na borda leste da Bacia do Paraná (Fig. 1), diamictitos polimíticos sotopostos à Formação Furnas constituem a Formação Iapó. Pelas similaridades litológicas e posição estratigráfica, abaixo dos arenitos da Formação Furnas e discordantemente sobre a sequência cambro-ordoviciana do Grupo Castro, portadora de vulcânicas com idade de $466 \pm 7$ Ma (Moro 1993), os diamictitos Iapó guardam ótima correlação com os diamictitos polimíticos da base da Formação Vila Maria, numa correspondência anteriormente aventada por Caputo \& Crowell (1985).

Se diamictitos ocorrem na mesma posição estratigráfica, em áreas tão distantes entre si, é previsível que ocorram também no interior da bacia, o que efetivamente acontece. 
Fácies similares foram descritas e referidas como Formação Iapó em vários poços da bacia, como sete metros de diamictitos sobrepostos por outro tanto de siltitos cinzentos no MO-1-PR (Monjolinho), ou os $73 \mathrm{~m}$ de diamictitos cortados no JT-1-PR (Joaquim Távora). No poço 2-RI-1-PR (Rio Ivaí, Fig. 3), já na calha central da bacia, diamictitos são capeados por siltitos cinza médios (profundidade 5118 a $5173 \mathrm{~m}$ ), correspondentes litológica e estratigraficamente às seções observadas em superfície na porção norte-noroeste da bacia (Formação Vila Maria) e em superfície e subsuperfície na porção leste (Formação Iapó).

$\mathrm{Na}$ faixa de afloramentos, os diamictitos Vila Maria são sobrepostos por folhelhos avermelhados e/ou cinza esverdeados, portadores de rica fauna marinha do Siluriano Inferior, mais especificamente Llandoveriano Inferior (Gray et al 1985). A deposição dos diamictitos é, portanto, de idade no mínimo llandoveriana inferior e no máximo ordoviciana inferior, mas não existem dados até o momento que permitam estabelecer com precisão o seu início. Por se situarem neste intervalo de tempo e serem considerados de origem glacial, são correlacionados à glaciação gondwânica no interregno Ordoviciano Superior/Llandoveriano Inferior, cujo máximo foi atingido no Neo-Ordoviciano (Ashgilliano Superior). É digno de menção lembrar que Maack (1947) já havia atribuído origem glacial para a Formação Iapó, considerando-a de idade siluriana.

A glaciação continental gondwânica neo-ordoviciana foi tão conspícua quanto a grande glaciação permo-carbonífera, deixando amplos registros espalhados em bacias de vários continentes, constituindo, entre outros exemplos, o Grupo Tichit na Bacia de Taoudeni no oeste da África (Deynoux 1985), as Formações Pakhuis da Bacia do Cabo na África do Sul (Rust 1981), Sarah e Zarqa no Oriente Médio (Vaslet
1990) e Don Braulio na Precordilheira argentina (Peralta \& Cárter 1990, Sánchezeí ai. 1991). Ao mesmo evento, podem ser correlacionados os diamictitos das formações Zapla no Peru (Laubacher et al. 1982) e Cancaniri e Sacta na Bolívia (Branisa et al 1972, Suarez-Soruco 1976). No Brasil, diamictitos interpretados como glaciais ocorrem na mesma posição estratigráfica nas Formações Trombetas da Bacia do Amazonas (Carozzi et al 1973) e Ipu da Bacia do Parnaíba (Caputo \& Lima 1984).

A existência deste nível de diamictitos na mesma posição estratigráfica, com pequena espessura e ampla distribuição geográfica na bacia, embora de ocorrência descontínua, materializa um evento episódico de magnitude regional, um marco estratigráfico muito útil à análise estratigráfica da sequência em que está inserido.

DISCORDÂNCIAS $\mathrm{Na}$ figura 3 , está representada a correlação entre o intervalo 5.118 a $5.286 \mathrm{~m}$ do 2-RI-1-PR (excluindo-se intrusiva mesozóica de 5.222 a $5.242 \mathrm{~m}$ ), o intervalo 1.702 a $1.944 \mathrm{~m}$ do 2-AG-1-MT e os perfis descritos por Faria (1982) na porção norte da bacia. Dela se depreende que os pelitos e diamictitos das formações Vila Maria e Iapó recobrem uma seção psamítica inferior, cuja assinatura em perfis de raios-gama e potencial espontâneo é caracterizada por deflexão à esquerda em direção ao topo.

Considerando serem os folhelhos e siltitos da Formação Vila Maria de idade llandoveriana inferior (Gray et al 1985), assim como a Formação Vargas Pena (Paraguai), e a extensão deste marco lito e bioestratigráfico para o interior da bacia (Assine \& Soares 1989), os psamitos sotopostos aos diamictitos tiveram sua deposição iniciada no Ordoviciano Superior, sendo correlates àqueles das Formações Cerro Jhú e ibbati do Grupo Caacupé (Paraguai), inclusive com a

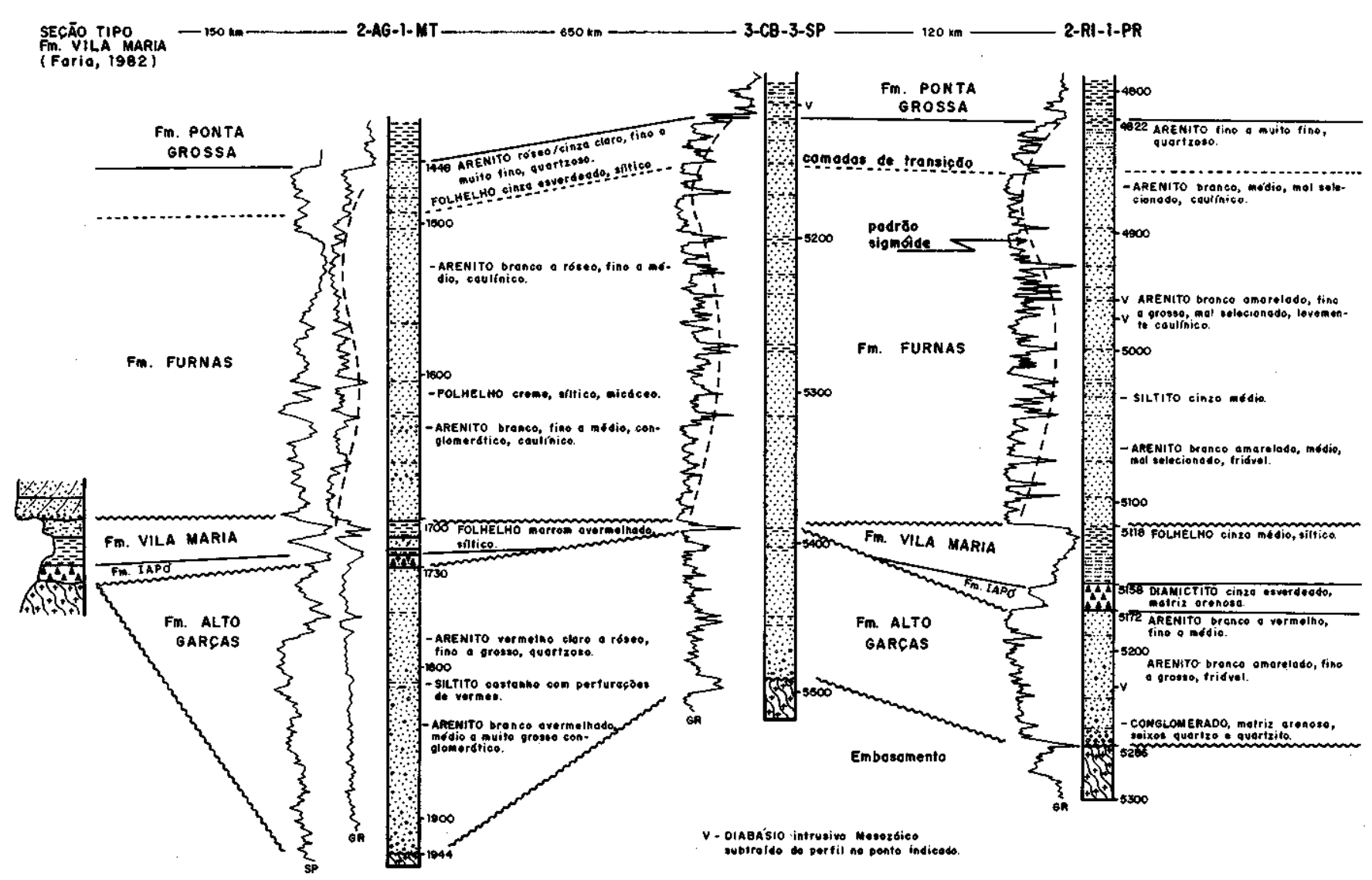

Figura 3 - Correlação estratigráfica das unidades mesopaleozóicas, segundo Assine \& Soares (1989)

Figure 3 - Stratigraphic correlation of Middle Paleozoic units. According to Assine \& Soares (1989) 




Figura 4 - Seção estratigráfica norte-sul (NS), construída a partir de perfis litológicos e de raios-gama, onde foram subtraídos os intervalos correspondentes a diabásios intrusivos mesozóicos (localização na Fig. 1)

Figure 4 - North-South cross-section based on gamma-ray logs and subsurface lithologic data. Diabase excluded. (Location on Fig. 1) 


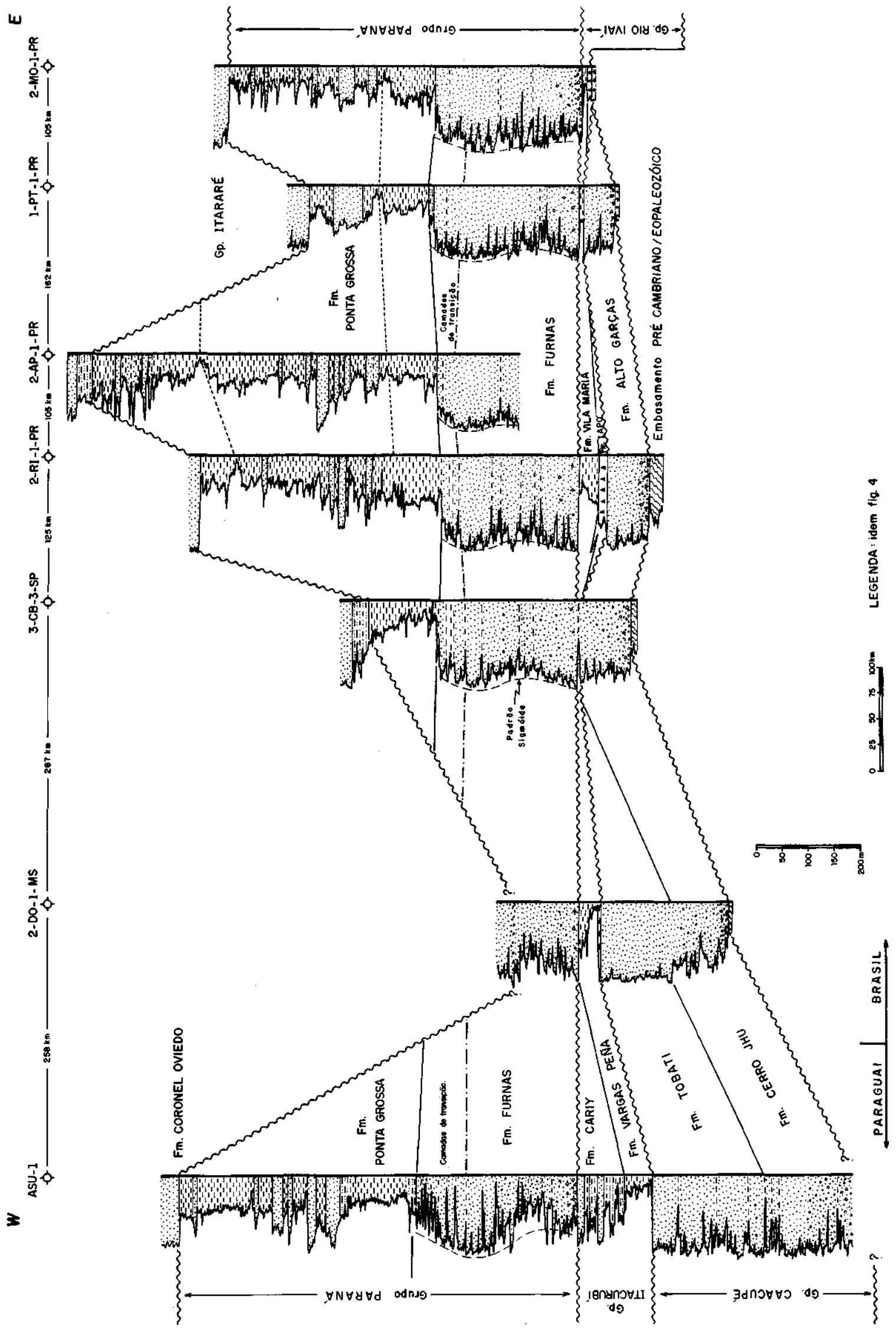

Figura 5 - Seção estratigráftca leste-oeste (EW), construída a partir de perfis litológicos e de raios-gama, onde foram subtraídos os intervalos correspondentes a diabásios intrusivos mesozóicos (localização na Fig. 1)

Figure 5 - East-West cros-section based on gamma-ray logs and subsurface lithologic data. Diabase excluded. (Location on Fig. 1) 
presença de conglomerados basais similares aos da Formação Paraguari do mesmo grupo.

Acima da seção pelítica da Formação Vila Maria, pode-se observar nos poços 2-AG-1-MT e 2-RI-1-PR a espessa seção siliciclástica da Formação Furnas, com mais de duas centenas de metros de espessura e típico padrão sigmóide nos perfis de raios-gama. $\mathrm{O}$ topo deste formato sigmóide corresponde às "camadas de transição" de Petri (1948), constituindo forte evidência a favor da inexistência de discordância entre as Formações Ponta Grossa e Furnas, conclusão a que chegaram também Popp \& Barcellos-Popp (1986).

Ainda na figura 3, pode-se observar no poço 3-CB-3-SP (Cuiabá Paulista) a presença da seção psamítica inferior com deflexão ascendente para a esquerda no perfil de raios-gama (intervalo 5.393 a $5.494 \mathrm{~m}$ ), correlata às seções sotopostas aos intervalos pelíticos da Formação Vila Maria, presentes nos outros dois poços. Neste poço, porém, tal seção pelítica não existe, estando os arenitos inferiores diretamente sotopostos aos da Formação Furnas (formato sigmóide), em contato marcado por um pico radioativo. Esta falta de seção indica que o contato entre a Formação Furnas e os sedimentos ordovício-silurianos é, este sim, discordante.

A própria natureza litológica dos sedimentos é sutilmente diferente dos da Formação Furnas, predominando arenitos mais finos e melhor selecionados, frequentemente com colorações avermelhadas no topo, observadas tanto em superficie quanto em subsuperfície.

As figuras 4 e 5 evidenciam que o padrão sigmóide da Formaçã̃o Furnas é repetitivo em vários poços, indicando um contato gradacional com a Formação Ponta Grossa. A pequena variação de espessura da unidade, ao longo de seções com extensão de centenas de km, é outra indicação de contato não-discordante.

Se o topo da Formação Furnas fosse discordante, era de se esperar falta de seção no topo da unidade em vários poços, como ocorre com a Formação Ponta Grossa, encimada por uma discordância (neodevoniana/eocarbonífera) que faz sua espessura variar extremamente através da bacia. O mesmo ocorre com a Formação Vila Maria, que em muitos poços não se encontra presente devido à remoção durante o episódio erosivo que gerou a discordância neo-siluriana.

\section{SEQUÊNCIAS TECTONO-SEDIMENTARES}

exposto, fica evidente a existência de duas grandes discordâncias regionais, uma neo-siluriana e outra neodevoniana/eocarbonífera, delimitando as sequências tectonosedimentares ordovício-siluriana e devoniana (Fig.6), o que corrobora as interpretações de Soares et al. (1978).

Sequência ordovício-siluriana A sequência ordovício-siluriana se apresenta com espessuras variáveis na porção brasileira da bacia, desde poucos metros a um valor máximo constatado de $362 \mathrm{~m}$ no poço 1-SE-1-SC (Seara). Apesar das irregularidades de distribuição (Fig. 7), existe uma tendência geral de espessamento para oeste em direção ao segmento paraguaio da bacia, onde são estimadas espessuras de $600 \mathrm{~m}$ (Wiens 1990), ou até mesmo de $1.100 \mathrm{~m}$ (Harrrington 1972). Isto pode ser visualizado na seção lesteoeste da figura 5, onde o poço ASU-1 (Assunção), perfurado pela Pecten, atravessou $533 \mathrm{~m}$ de sedimentos ordovíciosilurianos, sem ter atingido o embasamento.

O empilhamento sedimentar completo é dado por conglomerados basais, encimados sucessivamente por arenitos continentais/marinhos, diamictitos glaciais, folhelhos marinhos transgressivos e arenitos marinhos regressivos, caracterizando um grande ciclo transgressivo-regressivo.

Os arenitos regressivos superiores foram constatados na faixa de afloramentos somente nas bordas sudoeste (Formação Cariy do Grupo Itacurubi, no Paraguai) e norte-noroeste da bacia (MT e GO). Considera-se que sua preservação naquelas áreas foi consequência de se situarem em posições mais distais em relação à borda original, permanecendo a seção superior da sequência abaixo do nível de base de erosão ao final do ciclo. No restante da bacia, o ciclo erosivo do Siluriano Superior removeu grande parte dos sedimentos depositados, ficando preservados em muitos poços somente os psamitos/psefitos basais. Blocos baixos, originados nos eventos de tectônica deformadora ao final do ciclo, permitiram que, localizadamente, houvesse maior preservação, o que é o caso do poço 1-SE-1-SC, onde foram perfurados 362 $\mathrm{m}$ da sequência ordovício-siluriana, sendo $112 \mathrm{~m}$ de sedimentos regressivos do topo.

Uma seção representativa, embora pouco espessa $(53 \mathrm{~m})$, pode ser observada em Barra do Garças (MT), borda norte da bacia, na subida do Morro do Cristo (Fig. 8). Naquela localidade, a espessura é bastante reduzida comparativamente aos $242 \mathrm{~m}$ atravessados no poço $2-\mathrm{AG}-1-\mathrm{MT}$, distante cerca de $180 \mathrm{~km}$, sendo basicamente devido à diminuição de espessura dos arenitos e conglomerados da base da sequência. As causas da variação da espessura da seção basal não estão ainda determinadas com clareza, podendo ser consequência tanto de irregularidades no embasamento quanto de falhamentos sindeposicionais da fase inicial do ciclo sedimentar.

Os diamictitos, registros da glaciação neo-ordoviciana, ocorrem em quase toda a bacia. Em subsuperfície não foram amplamente reconhecidos pêlos geólogos de poço por três motivos básicos: a. devido à sua pequena espessura e tipo de amostragem, sua identificação em amostras de calha é muito difícil; b. como nos prospectos não eram previstos diamictitos em níveis estratigráficos dentro da Formação Furnas, atenção em identificá-los não foi despertada; c. diamictitos descritos nos intervalos correspondentes ao seu nível estratigráfico foram considerados desabados das paredes, provindos da seção sedimentar do Grupo Itararé atravessada acima pêlos poços.

Pela extensão, pequena espessura, deposição direta sobre o embasamento em várias localidades, tanto na borda leste quanto na norte, são considerados depósitos glaciais continentais, preservados pelo recobrimento por pelitos marinhos na rápida transgressão do Llandoveriano Inferior, estes materializando uma superfície de máxima inundação.

A seção dos diamictitos foi inicialmente denominada Formação Iapó (Maack 1947). Faria (1982) incluiu-os na base da Formação Vila Maria, por ele definida. A denominação Vila Maria foi estendida aos arenitos basais por Andrade \& Camarço $(1980,1982)$ e pelo próprio Faria (1982). Por último, Zalán et al. (1987) propuseram a formalização da Formação Rio Ivaí, incluindo os arenitos basais, os diamictitos e os folhelhos superpostos (intervalo 5.045 a $5.286 \mathrm{~m}$ do poço 2-RI-l-PR). Destas considerações, observa-se que há uma superposição das denominações litoestratigráficas em relação ao empilhamento sedimentar da sequência.

Propomos que, pela sua extensão e por constituírem um intervalo de importância na história geológica da bacia, os diamictitos sejam tratados como uma unidade distinta, mantendo-se, por questão de prioridade, a designação original de Formação Iapó. Decorrência natural desta proposição, serão considerados como Formação Vila Maria somente os folhelhos e arenitos associados do topo da sequência. Para a seção psamítica/psefítica basal é adotada a denominaçã. Alto Garças de Assine \& Soares (1989), na categoria de formação, já que tais sedimentos estão muito bem caracterizados e foram descritos pela primeira vez no poço Alto Garças n ${ }^{\circ} 1$ (2-AG-1-MT).

A designação Rio Ivaí, proposta na categoria de formação para designar a seção arenosa basal, é imprópria na extensão que lhe foi dada na seção-tipo, ou seja, no intervalo 


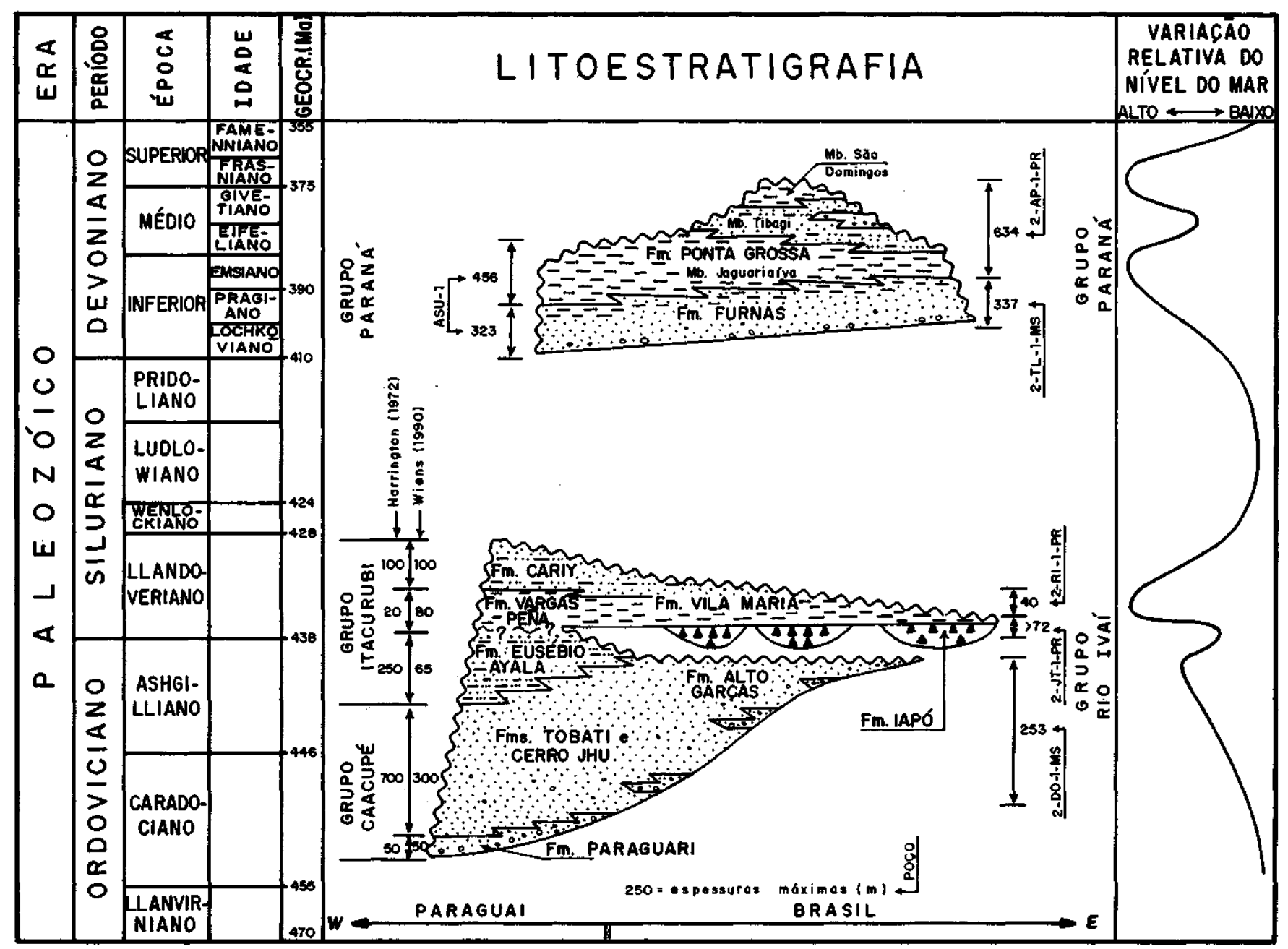

Figura 6 - Coluna estratigráfica das sequências ordovício-siluriana e devoniana da Bacia do Paraná Figure 6 - Stratigraphic chart for the Ordovician-Silurian and Devonian sequences of the Paraná basin

5.045 a 5.286 m do poço Rio Ivaí $\mathrm{n}^{\mathrm{e}} 1$ (Fig. 2), pois engloba os arenitos e conglomerados da Formação Alto Garças, os diamictitos da Formação Iapó, os folhelhos da Formação Vila Maria e a porção basal da Formação Furnas. No entanto, é apropriada para designar todo o pacote abaixo da Formação Furnas (Fig. 3). Propomos, assim, seja o termo Rio Ivaí elevado à categoria de grupo, englobando o conjunto das Formações Alto Garças, Iapó e Vila Maria, que compõem a sequência ordovício-siluriana da Bacia do Paraná no Brasil.

Apresentamos, a seguir, a caracterização das três formações que constituem o Grupo Rio Ivaí, onde incluímos considerações sobre correlações com as unidades aflorantes na porção paraguaia da Bacia do Paraná. Uma análise estratigráfica mais detalhada, incluindo dados palinológicos e um maior acervo de dados de subsuperficie, pode ser encontrada em Milani et al (no prelo).

FORMAÇÃO ALTO GARÇAS A Formação Alto Garças é aqui proposta para designar a seção arenosa basal da sequência ordovício-siluriana no Brasil. Assenta-se diretamente sobre o embasamento da bacia, constituído por rochas pré-cambrianas e eopaleozóicas (intrusivas do final do ciclo Brasiliano e molassas cambro-ordovicianas), e ocorre estratigraficamente abaixo da Formação Iapó ou diretamente sotoposta aos folhelhos da Formação Vila Maria. Em ambas as situações, o contato é abrupto, decorrência de diastemas produzidos pela variação do nível de base quando do advento da glaciação neo-ordoviciana.

$\mathrm{Na}$ sua base acham-se presentes conglomerados esbranquiçados ou avermelhados, com seixos predominantemente de quartzo e matriz arenosa feldspática. Nem sempre está presente e, quando ocorre, sua espessura é variável, não tendo sido constatados valores maiores que $30 \mathrm{~m}$. Em direção ao topo, passam a predominar arenitos feldspáticos conglomeráticos, cuja proporção de seixos decresce paulatinamente, encontrando-se no topo arenitos finos a médios, brancos ou róseos, subangulares a arredondados, muito friáveis. Os intervalos 1.730 a $1.944 \mathrm{~m}$ do poço 2-AG-1-MT e 5.172 a 5.286 m do 2-RI-l-PR são indicados como seçãotipo da unidade (Fig. 3).

O perfil vertical é de granodecrescência ascendente, embora o formato dos perfis de raios-gama sugira o contrário. Tal discrepância pode ser atribuída ao aumento da porcentagem dos feldspatos em direção à base, resultando em valores maiores de radioatividade.

Além de sua ocorrência na região de Barra do Garças (MT), já referidas, exposições da unidade podem ser observadas em estradas de acesso ao Pantanal Matogrossense, a partir das cidades de Rio Verde do Mato Grosso e Coxim(MS).

Os arenitos conglomeráticos apresentam estratificações cruzadas de médio porte, tabulares planares e acanaladas, frequentemente com níveis de seixos nas camadas frontais 


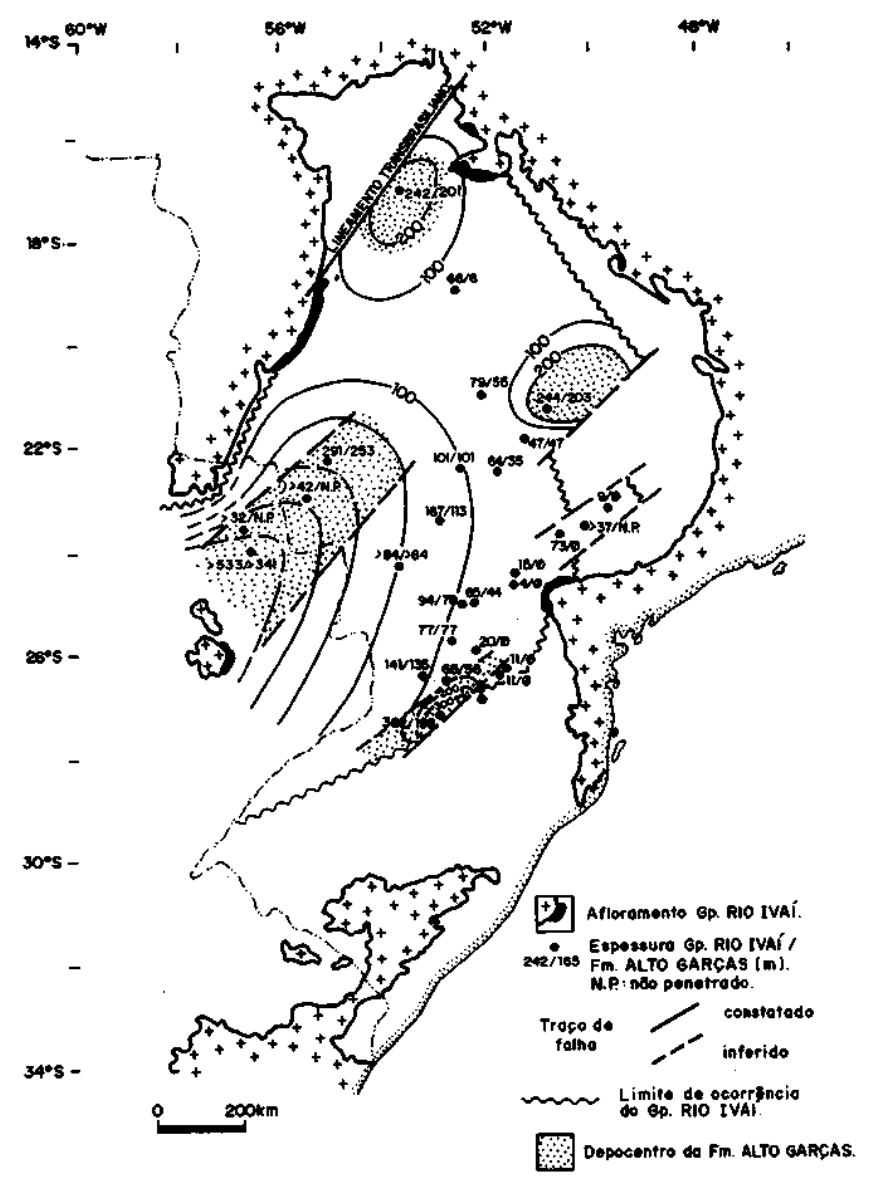

Figura 7 - Mapa de isópacas do Grupo Rio Ivaí (Milani et al. no prelo)

Figure 7 - Isopach map of the Rio Ivaí Group (Milani et al. in print)


Figura 8 - Seção colunar do Grupo Rio Ivaí, na estrada de acesso ao Morro do Cristo, em Barra do Garças (MT)

Figure 8 - Colunar-section of the Rio Ivaí Group. Road to Morro do Cristo, Barra do Garças, Mato Grosso State ou nos limites dos sets, sendo interpretados, juntamente com os conglomerados basais, como de origem fluvial. Na porção superior, onde os arenitos são de granulometria média a fina, textural e mineralogicamente mais maduros, foram observadas estratificações com truncamento por ondas, denotando condições marinhas litorâneas.

Do ponto de vista paleontológico, sabe-se apenas da presença de icnofósseis, constatados em testemunhos do poço 2-AG-1-MT, que não permitem uma datação da unidade. Pela posição estratigráfica, abaixo dos diamictitos da Formação Iapó, depositados no interregno Ashgilliano Superior/Llandoveriano Inferior, e por correlação com o Grupo Caacupé, é admitida uma idade ordoviciana superior (Caradociano/Ashgilliano) para os sedimentos da Formação Alto Garças.

FORMAÇÃO IAPÓ A Formação Iapó foi definida por Maack (1947) na Serra de São Joaquim, nas proximidades da cidade de Castro (PR). Na seção-tipo, sobre rochas cambro-ordovicianos do Grupo Castro, ocorrem 14,5 m de diamictitos avermelhados com clastos polimíticos (granitos, gnaisses, quartzitos, filitos, vulcânicas) de dimensões variadas, capeados por $2,0 \mathrm{~m}$ de siltitos cinza azulados com seixos, que são sobrepostos erosivamente por arenitos da Formação Furnas.

Por ser pouco espessa e descontínua em sua área de afloramento, onde raramente ultrapassa duas dezenas de metros, e por situar-se no sopé da escarpa da Formação Furnas, onde acumulam-se depósitos de tálus, afloramentos da unidade tem sido pouco relatados. Exposições podem ser observadas nas rodovias Castro-Tibagi e PiraíVentania, no Estado do Paraná, onde se apresentam em discordância angular por sobre os sedimentos cambroordovicianos do Grupo Castro, e em contato erosivo por sob os arenitos conglomeráticos da Formação Furnas. $\mathrm{Na}$ rodovia Piraí-Ventania, os diamictitos são capeados por uma camada de cerca de um metro de siltitos cinza-claro, sobre a qual acham-se presentes arenitos conglomeráticos da Formação Furnas, com evidências de ligeira angularidade (Fig. 9).


Figura 9-Seção colunar do Grupo Rio Ivaí, no Km 11 da Rodovia Piraí-Ventania (PR)

Figure 9 - Colunar-section of the Rio Ivaí Group. Piraí-Ventania highway km 11, Paraná State

Em São Luiz do Purunã, entre Curitiba e Ponta Grossa, diamictitos marrom-avermelhados ocorrem abaixo da Formação Furnas, apresentando seixos e matacões das mais diversas litologias, frequentemente facetados e estriados, tendo sido incluídos anteriormente nas molassas da Formação Camarinha (Popp 1972). A presença de seixos daquela 
unidade e a posição estratigráfica e estrutural indicam que tais diamictitos fazem parte da cobertura cratônica, constituindo a Formação Iapó.

Pelas razões expostas anteriormente, os diamictitos basais com ocasionais intercalações delgadas de folhelhos e arenitos, e espessuras variáveis que não ultrapassam em muito os $10 \mathrm{~m}$, descritos por Faria (1982) como pertencentes à porção inferior da Formação Vila Maria, constituem a própria Formação Iapó, e como tal sugerimos devam ser considerados (Fig. 10).

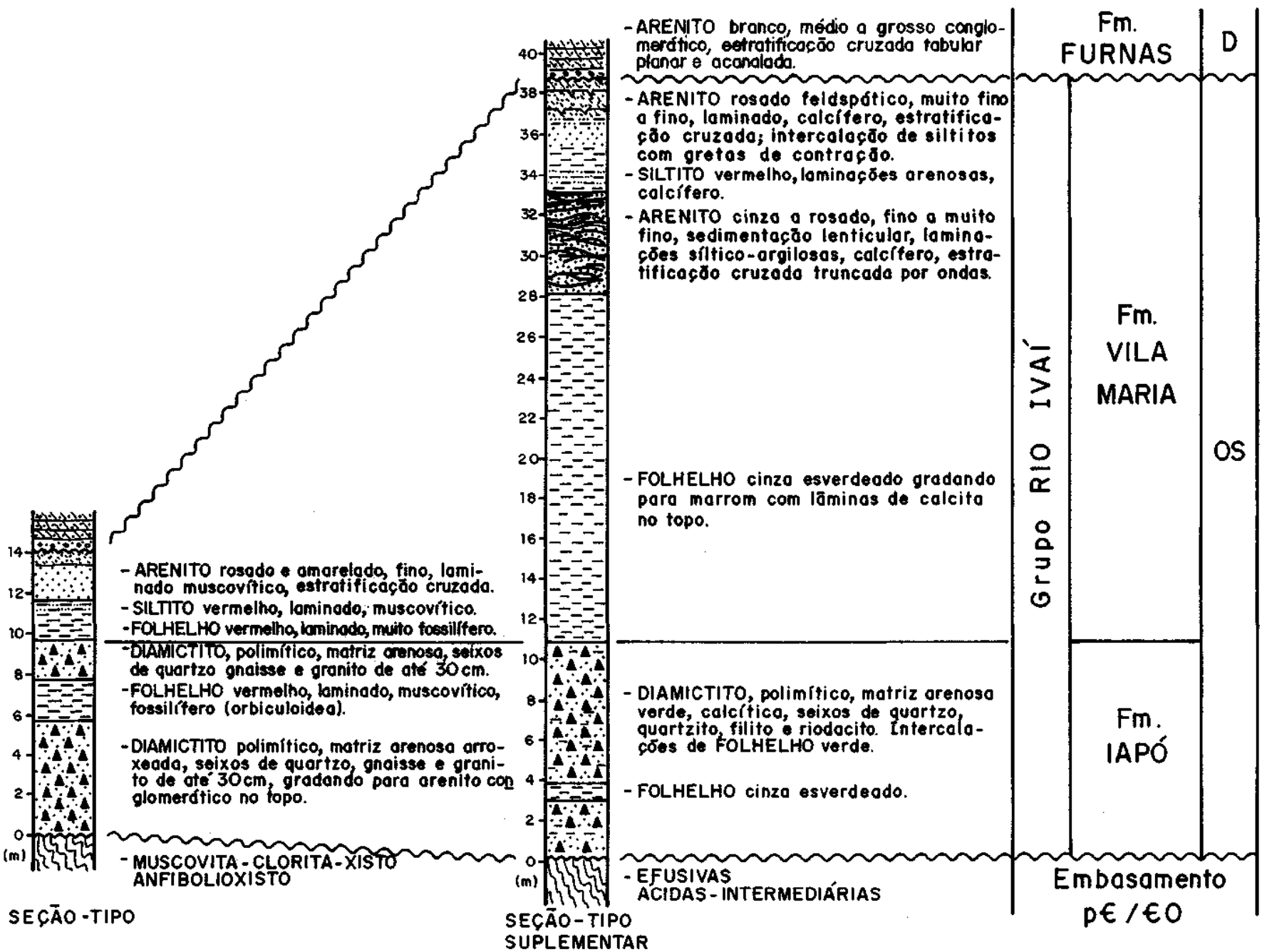

Figura 10 - Seção-tipo da Formação Vila Maria (modificado de Faria 1982)

Figure 10 - Type-section of Vila Maria Formation (Modified from Faria 1982)

Como já discutido anteriormente, os diamictitos estão recobertos pêlos folhelhos eollandoverianos da Formação Vila Maria e sobrepostos aos sedimentos cambro-ordovicianos do Grupo Castro. Sua associação à glaciação neo-ordoviciana permitiu posicionar a Formação Iapó no Ashgilliano Superior/Llandoveriano Inferior.

O contato inferior é frequentemente abrupto, dado por diamictitos sobrepostos erosivamente a arenitos da Formação Alto Garças. Tal descontinuidade no registro é interpretada como consequência do abaixamento do nível do mar durante a glaciação, expondo os sedimentos aos processos erosivos subaéreos decorrentes do rejuvenescimento da drenagem continental. Em afloramentos no Estado do Paraná, diamictitos assentam-se diretamente sobre o embasamento pré-cambriano/eopaleozóico, situação em que diamictitos terrestres (tilitos) foram preservados pelo recobrimento rápido em onlap, por folhelhos transgressivos da Formação Vila Maria.
Para oeste, no sentido do mergulho deposicional da bacia, a descontinuidade ainda pode ser constatada no poço ASU1 , já no Paraguai. Mais a oeste ainda, na faixa de afloramento paraguaia, em sedimentos originalmente mais distais, hoje soerguidos pelo Arco de Assunção, tal descontinuidade ainda não foi observada, podendo mesmo não existir. Também não foram constatados diamictitos Iapó, cuja seção é interpretada como cronocorrelata à dos sedimentos marinhos rasos da Formação Eusébio Ayala do Grupo Itacurubi (Fig. 
seu intervalo de ocorrência é incerto, incluindo também o Ordoviciano. Utilizando esporos de plantas e fitoplâncton (acritarcas e prasinófitos) posicionaram a Formação Vila Maria no Landoveriano Inferior. Esta datação foi confirmada por Grahn (1992), a partir do estudo de quitinozoários encontrados nos folhelhos da unidade.

Tais datações permitem a correlação lito, bio e cronoestratigráfica entre a Formação Vila Maria e a Formação Vargas Pena do Grupo Itacurubi, aflorante no Paraguai e posicionada no Llandoveriano Inferior/Médio por Wood \& Miller (1991) e Gray et al. (1992).

A seção areno-siltosa superior é constituída por arenitos finos, bem selecionados, moscovíticos, que apresentam estratificações cruzadas e laminações truncadas por ondas, com intercalações de siltitos róseos com moldes de conchas, numa faciologia indicativa de ambiente deposicional marinho raso. Gretas de contração, relatadas por Faria (1982), são indicativas de exposições periódicas, sob a ação de marés. Boas exposições podem ser observadas, nas localidades de Baliza e Barra do Garças (Fig. 8), no Mato Grosso, e nas proximidades de Coxim, no Mato Grosso do Sul

Conforme já discutido anteriormente, estes arenitos superiores representam a parte regressiva do ciclo ordovíciosiluriano, admitindo correlação com a Formação Cariy do Grupo Itacurubi, presente na porção paraguaia da bacia.

Sequência devoniana A sequência devoniana se apresenta mais completa, com espessura máxima estimada em cerca de $900 \mathrm{~m}$. Inicia-se com uma seção psamítico/ psefítica continental, que paulatinamente, com recorrência de fácies, passa a comportar sedimentos litorâneos e marinhos de água rasa, compondo a parte basal de um grande ciclo transgressivo-regressivo.

A transgressão é rápida e os folhelhos marinhos da Formação Ponta Grossa, recobrem os arenitos da Formação Furnas, sem que haja interdigitação significativa entre as mesmas. O contato entre ambas é gradual, caracterizando um intervalo no topo da Formacão Furnas conhecido como "camadas de transição" (Petri 1948).

Na seção de folhelhos marinhos da Formação Ponta Grossa, duas superfícies de máxima inundação (Ensiano e Givetiano) podem ser distinguidas, fazendo parte do evento transgressivo global do Devoniano médio.

Ao final do ciclo, eventos de tectônica deformadora causaram movimentação diferenciada, com reativação de estruturas rúpteis do embasamento, promovendo soerguimento de blocos e acentuada erosão dos sedimentos da Formação Ponta Grossa, cuja espessura varia muito ao longo da bacia (Figs. 4 e 5).

FORMAÇÃO FURNAS Na parte inferior da Formação Furnas predominam arenitos feldspáticos/caolínicos grossos, texturalmente imaturos. $\mathrm{Na}$ base, ocorrem, descontinuamente, arenitos conglomeráticos e conglomerados quartzosos. Para o topo, a quantidade de feldspatos decresce, passando a predominar arenitos granulometricamente mais finos, aos quais se entremeam níveis micáceos e/ou argilosos. Estratificações cruzadas, de vários tipos, são feições comuns, tendo sido analisadas em detalhe por Bigarella et al (1966).

Muitas têm sido as divergências quanto ao seu ambiente de sedimentação, se marinho (Lange \& Petri 1967, Bigarella 1973) ou fluvial (Schneider et al 1974, Zalán et al. 1987, Pereira \& Bergamaschi 1989). Os estudos realizados permitiram verificar que faciologicamente a unidade não é homogénea e que há recorrência de fácies continentais e litorâneas.

Integrando a parte inferior de um grande ciclo transgressivo-regressivo, cujo ápice de transgressão situa-se nos folhelhos da Formação Ponta Grossa, a Formação Furnas foi depositada em condições transgressivas, com onlap costeiro de oeste para leste. Desta forma, a unidade é mais jovem para leste, onde se depositou diretamente sobre o embasamento pré-cambriano/eopaleozóico, extravasando os limites orientais da sequência ordovício-siluriana.

O trato deposicional proposto é o de sistemas de deltas construídos por rios entrelaçados (braid deltas de McPherson et al. 1987). Enquanto ocorria progradação nos lobos ativos, os lobos abandonados eram afogados, colonizados por organismos (icnofósseis) ou retrabalhados pelas ondas e marés (fácies litorâneas). Novos lobos, sendo construídos sobre os mais antigos, causaram recorrência de fácies na vertical.

Apesar de alto, o aporte não foi suficiente para promover regressão, resultando num empilhamento retrogradacional. Estas relações indicam que a deposição se desenvolveu com aumento de influência marinha em direção ao topo, culminando com as camadas de transição. Este intervalo, descrito originalmente na faixa de afloramentos do Estado do Paraná, e caracterizado por uma diminuição da granulometria e aumento do teor de argila em direção ao topo, foi detectado em quase todos os poços da bacia, constituindo o topo de um formato sigmóide em perfis de raios-gama, típico da unidade (Figs. 3, 4 e 5).

Às novas correlações permitiram verificar que a espessura da unidade é pouco variável ao longo da bacia, situandose no geral entre 230 e $260 \mathrm{~m}$ (Fig. 11). A maior espessura constatada é de $337 \mathrm{~m}$ no poço 2-TL-í-MS (Três Lagoas), onde o valor é excepcionalmente alto em função da grande espessura das camadas de transição (Fig. 4).

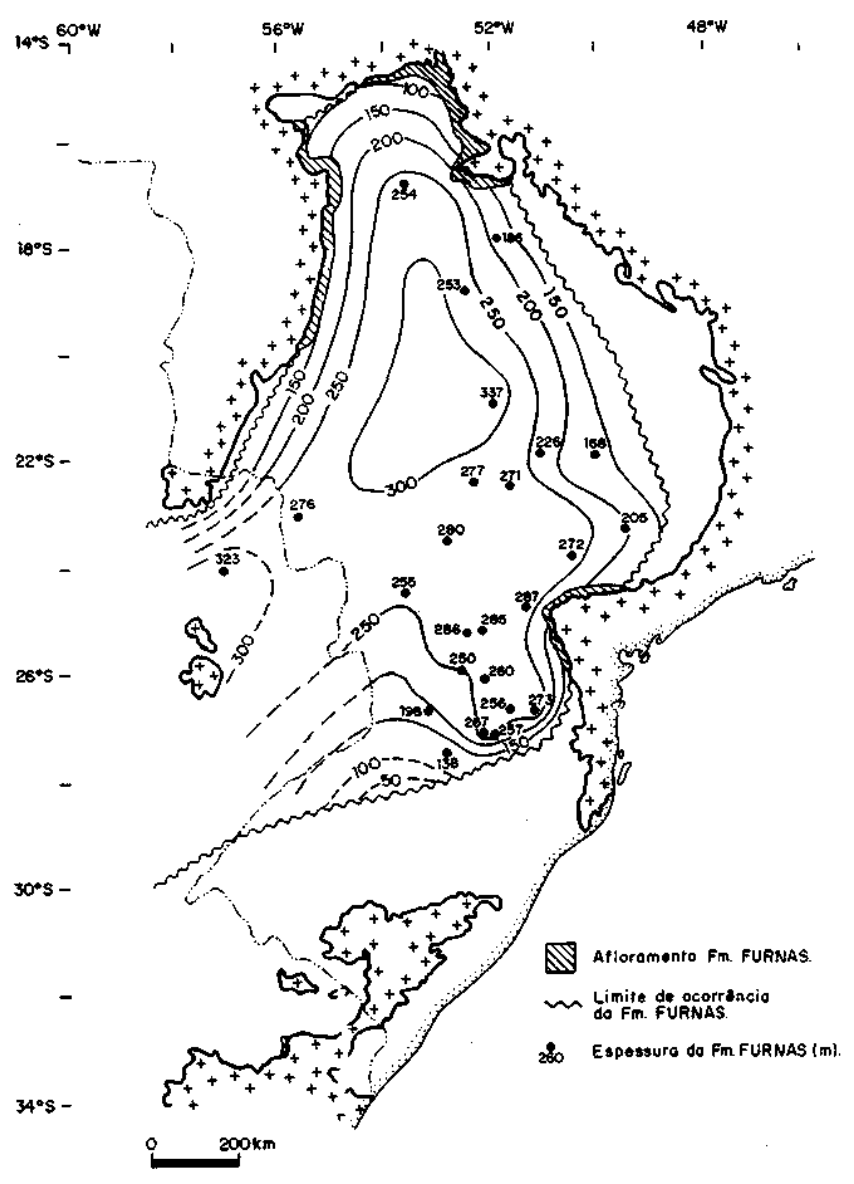

Figura 11-Mapa de isópacas da Formação Furnas (Milani et al. no prelo)

Figure 11 - Isopach map of the Furnas Formation (Milani et al. in print) 
Como já referido anteriormente, os poucos fósseis descritos até o momento, sobretudo icnofósseis, não permitem uma datação segura. Pesquisas realizadas na porção superior da unidade (Rodrigues et al. 1989) permitiram a identificação de restos vegetais (Psilophytales), que se distribuem do Siluriano Superior ao Devoniano Médio. Tendo em vista o contato concordante com os folhelhos emsianos da Formação Ponta Grossa e a deposição com nível de mar ascendente, a idade da Formação Furnas é considerada eodevoniana.

FORMAÇÃO PONTA GROSSA A Formação Ponta Grossa é constituída, da base para o topo, pelos Membros Jaguariaíva, Tibagi e São Domingos (Lange \& Petri 1967). Caracterizado por folhelhos cinzentos marinhos, com intercalações de arenitos finos retrabalhados por ondas em plataforma terrígena rasa, o Membro Jaguariaíva representa o afogamento dos sistemas deltaicos da Formação Furnas no Emsiano.

A grande transgressão global do Devoniano Médio Superior, que na Bacia do Paraná atingiu o máximo no Givetiano com a deposição dos folhelhos cinza-escuros do Membro São Domingos, foi interrompida temporariamente, durante o Eifeliano, pelo avanço de sistemas deltaicos provindos de leste e nordeste (Andrade \& Camarço 1980, Popp \& Barcellos-Popp 1986). A consequente regressão progradacional, que definiu assim duas significativas superfícies de máxima inundação (Emsiano e Givetiano) durante a transgressão devoniana, teve como consequência a deposição de arenitos na porção média da unidade, numa seção referida litoestratigraficamente como Membro Tibagi.

As causas deste avanço estão relacionadas à reativações tectônicas nas áreas-fonte, que promoveram aumento no aporte de terrígenos, o que é particularmente evidente no flanco nordeste, onde espessa cunha clástica deltaica, inclusive com intervalos conglomeráticos, interpôs-se entre os folhelhos marinhos.

Apesar de ocorrer em grande parte da bacia, a Formação Ponta Grossa apresenta suas maiores espessuras em dois grandes baixos estruturais, onde inclusive a parte regressiva do ciclo está parcialmente preservada. Sedimentos regressivos frasnianos foram constatados no topo da unidade em pouquíssimos poços, destacando-se o 2-AP-1-PR (Apucarana), onde foram atravessados $654 \mathrm{~m}$ da Formação Ponta Grossa, a máxima espessura constatada até o presente.

CONCLUSÕES As sequências ordovício-siluriana e devoniana constituem dois grandes ciclos transgressivoregressivos, separados por discordâncias regionais. Os fo- lhelhos das Formações Vila Maria/Vargas Pena e Ponta Grossa registram duas grandes transgressões, respectivamente, no Siluriano Inferior (Llandoveriano) e no Devoniano Médio (Givetiano). Os sedimentos regressivos do topo de cada sequência acham-se erodidos na maior parte da porção brasileira da bacia, ocorrendo apenas local e restritamente.

A sequência ordovício-siluriana constitue a sequência cratônica basal da Bacia do Paraná. Identificada inicialmente na porção paraguaia da bacia (Grupos Caacupé e Itacurubi), é representada no Brasil pelo Grupo Rio Ivaí (proposição deste trabalho), definido litoestratigraficamente, da base para o topo, como o conjunto das Formações Alto Garças (nova unidade), Iapó e Vila Maria (redefinida). Tais unidades, que afloram descontinuamente nas bordas norte-noroeste e leste, ocorrem extensivamente em subsuperfície, podendo ser rastreadas através de grande parte da bacia.

Os diamictitos da Formação Iapó são o registro da grande glaciação gondwânica neo-ordoviciana, constituindo um marco estratigráfico muito útil na análise estratigráfica da sequência. As causas de sua não constatação até o momento na porção paraguaia da bacia devem ser investigadas, já que unidades correlatas litológica e temporalmente estão presentes em bacias espalhadas em vários continentes, outrora parte do continente de Gondwana.

A sequência devoniana é constituída pelas Formações Furnas e Ponta Grossa, compondo o Grupo Paraná. A Formação Furnas apresenta espessura pouco variável ao longo da bacia e típico formato sigmóide nos perfis de raios-gama dos poços. Seu contato com a Formação Ponta Grossa é gradacional, materializado pelas camadas de transição. Na Formação Ponta Grossa, dois picos de máxima inundação marinha são reconhecidos (Membros Jaguariaíva e São Domingos), separados por um evento regressivo progradacional (Membro Tibagi).

Agradecimentos Os autores externam seus agradecimentos à Petrobrás, pelo acesso aos dados da empresa e autorização para publicação dos perfis apresentados; à Secretaria de Minas e Energia do Ministério de Obras Públicas e Comunicações do Paraguai, que proporcionou, por intermédio da Petropar, perfis e amostras de calha dos poços ASU-1 e ASU-2, para uso exclusivo no presente projeto; aos geólogos paraguaios Fernando Wiens, Ornar Ferreiro e Delio Orue, pela participação nos trabalhos de campo na seção paraguaia da bacia; ao desenhista Elmo Fernandes de Oliveira, pelas ilustrações; à Finep/ PADCT (processo $n^{\circ} 006591030300$ ) e ao CNPq (processo $\mathrm{n}^{\mathrm{o}} 500848 / 91$ ), que nos proporcionaram o apoio financeiro necessário ao desenvolvimento do trabalho.

\section{REFERÊNCIAS BIBLIOGRÁFICAS}

ANDRADE, S.M. \& CAMARÇO, P.E.N. 1980. Estratigrafia dos sedimentos devonianos do flanco nordeste da Bacia do Paraná. In: CONGR. BRÁS. GEOL., 31. Camboriú, 1980. Anais... Camboriú, SBG. v. 5, p. 2828-2836.

ANDRADE, S.M. \& CAMARÇO, P.E.N. 1982. Sequências sedimentares pré-carboníferas dos flancos nordeste da Bacia do Paraná e sudoeste da Bacia do Parnaíba e suas possibilidades uraníferas. In: CONGR. BRÁS. GEOL., 32. Salvador, 1982. Anais... Salvador, SBG. v. 5, p. 2132-2144.

ASSINE, M.L. \& SOARES, P.C. 1989. Correlações nas sequências mesopaleozóicas da Bacia do Paraná. Acta Geol. Leopold., 12(29):39-48.

BIGARELLA, J.L 1973. Paleocorrentes e deriva continental (comparação entre África e América do Sul). Boi. Paraná. Geociênc., 31:141-224.

BIGARELLA, J.J.; SALAMUNI, R.; MARQUES, P.L., F $\mathrm{F}^{8} 1966$. Estruturas e texturas da Formação Furnas e sua significação paleogeográfica. Boi. Paraná. Geociênc., 18:1-114. (Geologia)
BRANISA, L.; CHAMOT, G.A.; BERRY, W.B.N.; BOUCOT, A.J. 1972. Silurian of Bolivia. In: BERRY, W.B.N. \& BOUCOT, A.J. ed. Correlaition of the South American Silurian rocks. Geol. Soe. Am. Spec. Paper, 133.

BURJACK, M.I.A. \& POPP, M.T.B. 1981. A ocorrência do icnogênero Arthrophycus no Paleozóico da Bacia do Paraná. Pesquisas, 14:163-167.

CAPUTO, M.V. \& CROWELL, J.C. 1985. Migration of glacial centers across Gondwana during Paleozoic Era. Geol. Soe. Am.. Buli., 96:1020-1036.

CAPUTO, M.V. \& LIMA, E.C. 1984. Estratigrafia, idade e correlação do Grupo Serra Grande - Bacia do Parnaíba. In: CONGR. BRÁS. GEOL., 33. Rio de Janeiro, 1984. Anais... Rio de Janeiro, SBG. v. 2, p. 740-753.

CAROZZI, A.V.; PAMPLONA, H.R.P.; CASTRO, J.C.; CONTREIRAS, C.J.A. 1973. Ambientes deposicionais e evolução tecto-sedimentar da seção elástica paleozóica da Bacia do Médio Amazonas. In: CONGR. BRÁS. GEOL., 27. Aracaju, 1973. Anais... Aracaju, SBG. v. 3, p. 279-314. 
DEYNOUX, M. 1985. Terrestrial or waterlain glacial diamictites? Three case studies from the Late Precambriam and Late Ordovician glacial drifts in West Africa. Palaeogeogr. Palaeoclimatol. Palaeoecol., 51:97-141.

FARIA, A. 1982. Formação Vila Maria - nova unidade litoestratigráfica siluriana da Bacia do Paraná Ciências da Terra, 3:12-15.

FARIA, A. \& REIS NETO, J.M. 1978. Nova unidade litoestratigráfica pré-Furnas no sudoeste de Goiás. In: CONGR. BRAS. GEOL. 30. Recife, 1978. Resumo das Comunicações... Recife, SBG. p. 136-137.

GRAHN C.Y. 1992. Revision of Silurian and Devonian strata of Brazil. Palinology, 16:35-61.

GRAY, J.; COLBATH, G.K.; FARIA, A.; BOUCOT, A.J.; ROHR, D.M. 1985. Silurian-age fossils from the Paleozoic Paraná Basin, Southern Brazil. Geology, 13:521-525.

GRAY J.; BOUCOT, A.J.; GRAHN C. HIMES, G T. 1994 A new record of Early Silurian-age land plant spores from the Paraná Basin, Paraguay. Geol. Mag., 129(6):741-752.

HARRINGTON, HJ. 1972. Silurian of Paraguay. In: BERRY, W.B.N. \& BOUCOT, A.J. ed. Correlation of the South American Silurian Rocks. Geol. Soe. Am.. Spec. Paper, 133:41-50.

LANGE, F.W. \& PETRI, S. 1967. The Devonian of the Paraná Basin. Boi. Paraná Geociênc., 21/22:5-55.

LAUBACHER, G.; BOUCOT, A.J.; GRAY, J. 1982. Additions to Silurian stratigraphy, lithofacies, biogeography e paleontology of Bolívia and Southern Peru. J. Paleontol, 56(5):1138-1170.

MAACK, R. 1947. Breves Notícias sobre a Geologia dos Estados do Paraná e Santa Catarina. Curitiba, Arquivos de Biologia e Tecnologia, v. 2, 63-154.

MAINO, U.M. 1965. Relatório Geológico Final, Poço 2-AG-l-MT. Ponta Grossa, PETROBRAS/DESUL. (Relatório Interno).

McPHERSON, J.C.; SHANMUGAN, G.; MOIOLA, R.J. 1987. Fan-deltas and braid deltas: varieties of coarse-grained deltas. Geol Soe. Am. Buli, 99:331-340.

MORO, R.X. 1993. A Bacia Ordoviciana do Grupo Castro - PR. Rio Claro. 157 p. (Dissertacão de Mestrado, IGCE-UNESP).

PERALTA, S.H. \& CARTER, C.H. 1990. La glaciacion gondwánica dei Ordovícico tardio: evidências en fangolitas guijarrosas de Ia Precordillera de San Juan, Argentina. In: CONGR. GEOL. ARGENT.,

11. San Juan, 1990. Actas... San Juan, AGA. v. II, p. 181-185.

PEREIRA, E. \& BERGAMASCHI, S. 1989. Estudo faciológico dos sedi-

mentos da Formação Furnas nas regiões de Ponta Grossa (PR) Castro (PR) e Tibagi (PR) - Bacia do Paraná. In: SIMP. GEOL. SUDESTE, 1. Rio de Janeiro, 1989. Boletim de Resumos... Rio de Janeiro, SBG. p. 1-2.

PETRI, S. 1948. Contribuição ao Estudo do Devoniano Paranaense. Rio de Janeiro, DNPM/DGM. 125 p. (Boletim 129).
POPP, J.H. 1972. Contribuicão à estratigrafia e sedimentologia da Formacão Camarinha (Pré-Devoniano do Estado do Paraná). Boi. Paraná. Geociênc., 30:3-71.

POPP, J.H. \& BARCELLOS-POPP, M.T. 1986. Análise estratigráfica dá sequência devoniana da Bacia do Paraná (Brasil). Rev. Brás. Geoc., 16(2):187-194.

POPP, M.T.B.; BURJACK, M.I.; ESTEVES, LR. 1981. Estudo preliminar sobre o conteúdo paleontológico da Formação Vila Maria (pré-Devoniano) da Bacia do Paraná. Pesquisas, 14:169-180.

RODRIGUES, M.A.C; PEREIRA, E.; BARGAMASCHI, S. 1989. Ocorrência de Psilophytales na Formacão Fumas, borda leste da Bacia do Paraná. Boi. IG-USP, Publ. Esp., 7:35-43.

RUST, I.C. 1981. Early Palaeozoic tillite, South África. In: HAMBREY, MJ. \& HARLAND, W.B. ed. Earth's Pre-Pleistocene Glacial Record. Cambridge, Cambridge University Press. p. 113-117.

SANCHEZ T.M. BENEDETTO, J.L; BRUSSA, E 1991. Late Ordovician stratigraphy, paleoecology, and sea levei changes in the Argentine Precordillera. In: BARNES, C.R. \& WILLIAMS, S.H. ed Advances in Ordovician Geology. Ontario, Geol. Surv. Can., p. 245-258. (Paper 90-9).

SCHNEIDER R.L.: MÜLMANN H. TOMMASI, E · MEDEIROS, R.A.; DAEMON, R.F.; NOGUEIRA, A.A. 1974. Revisão estratigráfica da Bacia do Paraná. In: CONGR. BRÁS. GEOL., 28. Porto Alegre, 1974. Anais... Porto Alegre, SBG. v. 1, p. 41-65.

SOARES, P.C. 1991. Tectônica Sinsedimentar Cíclica na Bacia do Paraná - Controles. Curitiba. 131 p. (Tese de Professor Titular, UFPR).

SOARES, P.C.; LANDIM, P.M.B.; FULFARO, V.J. 1978. Tectonic cycles and sedimentary sequences in the Brazilian intracratonic basins. Geol. Soe. Am.. Buli, 89:181-191.

SUAREZ-SORUCO, R. 1976. El Sistema Ordovícico en Bolívia. Rev. Tecn. YPFB, 5(2): 111-223.

VASLET, D. 1990. Upper Ordovician glacial deposits in Saudi Arábia. Episodes, 13(3):147-161.

WIENS, F. 1990. Estratigrafia Fanerozoica Resumida dei Paraguay. Assuncão, Geoconsultores. 6 p. (Relatório Interno).

WOOD, G.D. \& MILLER, M.A. 1991. Distinctive Silurian chitinozoans from the Itacurubi Group (Vargas Pena Shale), Chaco Basin, Paraguay. Palynology, 15:181-192.

ZALÂN, P.V.: WOLFF, S. CONCEICÃO, JC.J; VIEIRA IS. ASTOLFI, M.A.M.; APPI, V.T.; ZANOTTO, O.A. 1987. A divisão tripartite do Siluriano da Bacia do Paraná. Rev. Brás. Geoc., 17(3):242-252.

MANUSCRITO A764

Recebido em 29 de junho de 1993 Revisão do autor em 3 dẹjaneiro de 1994 Revisão aceita em 21 de janeiro de 1994 